\title{
Risk Factors Associated with Porcine Leptospirosis in Uttar Pradesh, India
}

\author{
Sujit Kumar Behera ${ }^{1}$, Sabarinath, $\mathrm{T}^{2 *}$, Rajeev Singh ${ }^{3}$, Abhishek Hota ${ }^{4}$, Shanmugham Chandra Sekar ${ }^{5}$, \\ Ashok Kumar ${ }^{6}$, Senthil Kumar ${ }^{7}$, Radhakrishna Sahu ${ }^{8}$, Med Ram Verma ${ }^{9}$, Ganesh Balasubramanian ${ }^{10}$ and \\ Ajayta Rialch ${ }^{11}$ \\ ${ }^{1}$ Department of Epidemiology and Public Health, Central University of Tamil Nadu, INDIA \\ ${ }^{2}$ Clinical Bacteriological Laboratory, ICAR-Indian Veterinary Research Institute (IVRI), Mukteswar, INDIA \\ ${ }^{3}$ Department of Microbiology, Sardar Vallabhbhai Patel University of Agriculture and Technology, Meerut, INDIA \\ ${ }^{4}$ Department of Animal Science, Centurion University of Technology and Management, Odisha, INDIA \\ ${ }^{5}$ Biochemistry Laboratory, ICAR-IVRI, Mukteswar, INDIA \\ ${ }^{6}$ Krishi Bhawan, ICAR, New Delhi, INDIA \\ ${ }^{7}$ Zoonosis Research Lab, Tamil Nadu Veterinary and Animal Sciences University, INDIA \\ ${ }^{8}$ Division of Veterinary Public Health, ICAR-IVRI, INDIA \\ ${ }^{9}$ Livestock Economics \& Statistics Division, ICAR-IVRI, INDIA \\ ${ }^{10}$ ICMR-National Institute of Epidemiology, Chennai, Tamil Nadu, INDIA \\ ${ }^{11}$ ICAR-IVRI, Palampur, Himachal Pradesh, INDIA \\ *Corresponding author: S Thankappan; E-mail:drsabari143ivri@gmail.com
}

Received: 19 June, 2021

Revised: 26 June, 2021

Accepted: 02 July, 2021

\begin{abstract}
Porcine leptospirosis is a zoonotic disease. Pigs act as reservoir host for various Leptospira serovars. A study aimed to pinpoint the risk factors of porcine leptospirosis was designed on pigs of three agro-climatic zones- Midwestern plain zone (Bareilly), Eastern Plain zone (Barabanki) and Southwestern semi- arid zone (Aligarh) of Uttar Pradesh. Risk factor analysis was done using pretested structured questionnaire. The univariate analysis of the variables of interest was done using Fisher's exact test/ Pearson's chi-square. Further, multivariate analysis was done through logistic regression model using serological status of animal in Microscopic Agglutination Test (MAT) as dependent variable. The overall seropositivity of 23.81\% (70/294; 95\% CI: $18.94 \%$ - 28.67\%) was recorded in MAT with Icterohaemorrhagiae as the leading serovar. Multivariate risk factor analysis revealed that accessibility of swine to unsanitary wallowing ponds (Odds ratio: $8.58 ; 95 \%$ CI: 3.34-21.93; P $<0.001$ ), contact of domesticated pigs with wild/feral pigs and water buffaloes (Odds ratio: 12.83; 95\% CI: 3.72-44.26; $\mathrm{P}<0.001$ ) and accessibility of swine to garbage pits (Odds ratio: 3.97; 95\% CI: 1.28-12.26; $\mathrm{P}<0.016$ ) were statistically significant. Further, risk factor analysis revealed that mature pigs of $>2$ years age had higher chance of contracting leptospirosis than young pigs of $<2$ years (Odds ratio: 12.09; 95\% CI: 2.92-50.03; $\mathrm{P}<0.001$ ) owing to higher probability for exposure to above mentioned risk factors. Domesticated pigs reared under mixed farming system that gets access to wallow in unsanitary ponds frequented by feral pigs and water buffaloes and pigs that access garbage pits frequented by rodents were at high risk of contracting leptospirosis.
\end{abstract}

\section{HIGHLIGHTS}

(0 Faulty swine husbandry practices are responsible for spread of porcine leptospirosis.

( Exacerbating factor responsible for porcine leptospirosis is providing pigs access to wallowing ponds frequented by water buffaloes.

Keywords: Leptospirosis; pig; risk factor; wallowing pond; water buffalo
How to cite this article: Behera, S.K., Sabarinath, T., Singh, R., Hota, A., Sekar, S.C., Kumar, A., Kumar, S., Sahu, R., Verma, M.R., Balasubramanian, G. and Rialch, A. (2021). Risk Factors Associated with Porcine Leptospirosis in Uttar Pradesh, India. J. Anim. Res., 11(04): 561570

Source of Support: None; Conflict of Interest: None

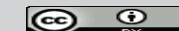


Leptospirosis is a zoonosis of ubiquitous distribution, found in virtually all tropical and temperate areas of the world, and possesses a broad host range affecting almost all mammals (Verma et al., 2020). This emerging public health problem is caused by spirochetes which are currently divided into 35 species classified into three phylogenetic clusters, which supposedly correlate with the virulence of the bacteria (Vincent et al., 2019). Leptospirosis is a burden to swine husbandry since it cause heavy economic losses due to a plethora of clinical manifestations spanning from infertility to spontaneous abortions which occur 2-4 weeks before completion of gestation period, stillbirth, foetal mummification and maceration, increased weaning-to-oestrus interval, decreased number of piglets per litter, birth of runt piglets, agalactia and reduced productivity (Wasinski, 2014; Divers, 2018; Pozzi et al., 2020). Swine serve as maintenance/reservoir hosts for serovars such as Bratislava, Pomona, Tarassovi Mitis and Muenchen (Lee et al., 2019; Bertasio et al., 2020), while serovars Canicola, Grippotyphosa, Icterohaemorrhagiae and Hardjo commonly cause incidental infections in pigs (Ellis, 1999; Strutzberg-Minder et al., 2018). In humans involved in swine husbandry, leptospirosis is known as "swine herder's disease" (Bhatia and Umapathy, 2015).

Risk factor analysis plays a pivotal role in pinpointing the managemental practices in swine husbandry which needs to be corrected in order to check the threat posed by porcine leptospirosis. Several studies performed in various countries highlighted the role of various risk factors such as rodents control failure, water mismanagement practices, higher number of female pigs in a breeding stock, sampling period especially during warm and wet weather, presence of swampy areas for pigs to wallow, pig farms housing other species of livestock, higher proportion of mature pigs, absence of quarantine facilities, stagnant water source, pig farms where healthy swine were bred with sick pigs, farm premises with flooded areas, and artificial insemination utilizing asymptomatic boars as aggravating factors associated with porcine leptospirosis (Valenca et al., 2013; dos Santos et al., 2019; Ngugi et al., 2019; Atherstone et al., 2020).

Perusal of literature revealed that porcine leptospirosis has been reported mostly in southern states of India such as Andhra Pradesh (Rani Prameela et al., 2013), Tamil Nadu (Bojiraj et al., 2017) and Kerala (Reshma et al., 2018). At present, there is a shortage of information with regard to seroprevalence of porcine leptospirosis in Northern India except for one study conducted in Uttar Pradesh (Behera et al., 2014). In India, where vaccination against porcine leptospirosis is not routinely practiced, the immediate requirement is identification of the risk factors and taking appropriate preventive measures to contain porcine leptospirosis. Hence, the present study was designed to study the seroprevalence of leptospirosis in the pigs of three agro-climatic zones- Midwestern plain zone (Bareilly), Eastern Plain zone (Barabanki) and Southwestern semi- arid zone (Aligarh) of Uttar Pradesh and to identify the risk factors responsible for porcine leptospirosis in these areas.

\section{MATERIALS AND METHODS}

\section{Study area, Target population and serum collection}

The study was approved by Institutional Animal Ethics Committee of ICAR - IVRI (Research Permit No: F.26$1 / 2015-16 / \mathrm{JD}(\mathrm{R})$ and the protocols followed during serum collection were strictly adhered according to protocols laid by Institutional Animal Ethics Committee of ICARIVRI. Based on multistage cluster sampling techniques, serum samples were collected from selected pigs of semi-intensive and backyard farms from one district each of three agro-climatic zones of Uttar Pradesh namely Southwestern semi- arid zone (Aligarh), Midwestern plain zone (Bareilly) and Eastern Plain zone (Barabanki) for a period of one year from July 2016 to June 2017. A total of 294 sera samples, including 212 sera samples from rural locations and 82 sera samples from peri-urban region were collected. Out of 212 sera sample of rural locations, the 61 were collected from Gursaina, HastpurIglas, Kajroth and Gandhi Gram villages of Aligarh, 36 from Fatehpur, Triveniganj and Dewa villages of Barbanki and 115 from Nekpur, Bhojipura, Richha, Faridpur and Baheri villages of Bareilly Districts (Fig. 1). The 82 sera samples from peri-urban region of Bareilly district included 32 sera samples from Chaupla \& Beharipur pig farms and 50 from pig farm located at Indian Veterinary Research Institute/ IVRI (Fig. 1). The study sample comprised of 230 male pigs and 64 female pigs of which 172 pigs were $<2$ years old while 122 pigs were $>2$ years old. A total of 113 pigs belonged to Large White Yorkshire breed while the rest 181 pigs were indigenous breeds. 


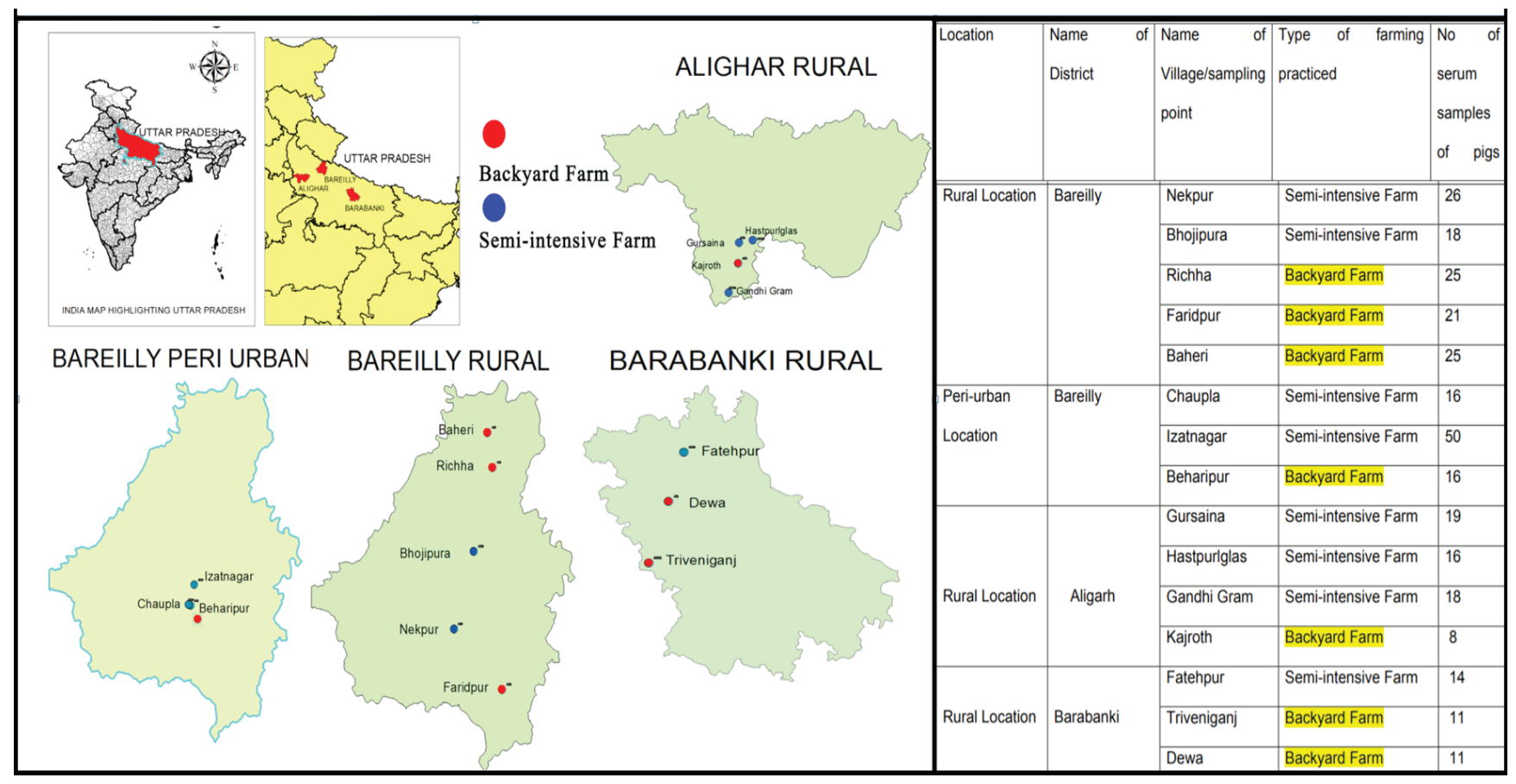

Fig. 1: Showing the location of pig farms where sampling has been done and type of pig farming adopted at each sampling point

\section{Study of risk factors}

A survey was conducted using a questionnaire with regard to general swine husbandry practices (rodent pest control, presence of other livestock species and accessibility of pigs for wallowing and scavenging in garbage pits) and demographic variables (breed, sex, age). The risk factor analysis was conducted using the data collected with the questionnaire tool. Multi-level logistic regression models were used to explore the association between risk factors for leptospirosis seropositivity in pigs and binary outcomes of MAT for each animal. A positive outcome in MAT was defined as any pig positive for at least one serovar in MAT at 1 in 100 titre. In this study, a pre-selection was performed in which all the variables were tested using models with just one explanatory variable at a time (univariate models) and afterwards included in the multivariate model only those significant variables that have shown a relaxed $\mathrm{P}$-value $(\mathrm{P}$ value $\leq 0.25)$. This pre-selection strategy using relaxed P-value criterion allowed in reducing the initial number of variables in the model reducing the risk of missing important variables (Sperandei, 2014). This model was adopted by epidemiologists while evaluating prognosis factors and risk factors for leptospirosis seropositivity in Guadeloupe and western Kenya respectively (Herrmann-
Storck et al., 2010; Cook et al., 2017). The univariate analysis of the variables of interest was done using either Fisher's exact test or Pearson's chi-square, with the level of significance $95 \%$ C.I. and $5 \%$ error rate in order to pinpoint the risk factors associated with Leptospira spp. seropositivity. Data were entered in Microsoft Excel 2013 and analyzed using SPSS version 22.

\section{Leptospira serovars and strains used in Microscopic agglutination test (MAT)}

A battery of 16 leptospiral serovars namely, Leptospira interrogans serovar Australis strain Ballico, L. interrogans serovar Autumnalis strain Akiyami A, L. interrogans serovar Ballum strain S102, L. interrogans serovar Bataviae strain van Tienen, L. interrogans serovar Canicola strain Hond Utrecht IV, L. kirschneri serovar Cynopteri strain 3522C, L. interrogans serovar Djasiman strain Djasiman, L. kirschneri serovar Grippotyphosa strain Moskva V, L. borgpetersenii serovar Hardjo-bovis strain JB197, L. interrogans serovar Hebdomadis strain Hebdomadis, L. interrogans serovar Icterohaemorrhagiae strain RGA, L. borgpetersenii serovar Javanica strain Veldrat Batavia 46, L. noguchii serovar Louisiana strain 
Table 1: Seroprevalence of Leptospiraserovars and serogroups by microscopic agglutination test (titre>1:100) among 294 porcine serum samples in Uttar Pradesh, India

\begin{tabular}{lllll}
\hline Genomo- Species & Serogroup/Serovar/Strain & Positive (N) $^{\dagger}$ & Prevalence (\%) $^{\text {95\% CI }}$ \\
\hline L. interrogans & Icterohaemorrhagiae/Icterohaemorrhagiae/RGA & 49 & 16.67 & $12.40-20.90$ \\
& Pomona/Pomona/Pomona & 31 & 10.54 & $7.0-14.10$ \\
& Australis/Australis/Ballico & 06 & 2.04 & $0.4-3.70$ \\
L kirshneri & Grippotyphosa/Grippotyphosa/Moskova V & 32 & 10.88 & $7.30-14.40$ \\
L. borgpetersenii & Tarassovi/Tarassovi/Perepelitsin & 28 & 9.52 & $6.20-12.90$ \\
\hline
\end{tabular}

$\mathrm{n}$, number of positive sera by MAT; ${ }^{\dagger}$ Cumulative figure $(\mathrm{N}=146)$ exceed total MAT positive sera $(\mathrm{n}=70)$ since several porcine sera tested positive for multiple serovars; CI, Confidence Interval of $95 \%$.

LSU 1945, L. interrogans serovar Pomona strain Pomona, L. interrogans serovar Pyrogenes strain Salinem and $L$. borgpetersenii serovar Tarassovi strain Perepelitsin were employed for performing MAT.

\section{Microscopic agglutination test (MAT)}

Porcine sera were screened for anti-leptospiral antibodies by MAT as previously described (USDA, 1987). Briefly, serum samples were diluted 1 in 50 in phosphate buffer saline (PBS) and a volume of leptospiral antigen, equal to the diluted serum volume, was added to each well, making the final serum dilution 1 in 100 . The 4-8 days old live leptospiral antigens (approx. $2 \times 10^{8}$ leptospires $/ \mathrm{ml}$ ) of 16 reference serovars were used. The microtitre plates were incubated for 2 hours at $29^{\circ} \mathrm{C}$ and the serum-antigen mixtures were examined using dark field microscopy. A positive outcome in MAT suggestive of exposure/ seropositivity was defined as any single serum sample found to have $>50 \%$ reduction in the number of free non-agglutinable leptospires in the test when compared to the control at 1 in 100 serum dilution for at least one leptospiral serovar.

\section{RESULTS}

Out of 294 sera tested at Aligarh, Bareilly and Barabanki districts of Uttar Pradesh, 70 sera tested positive in MAT and maximum seropositivity was detected for serovar Icterohaemorrhagiae $(n=49)$, followed by Grippotyphosa $(n=32)$, Pomona $(n=31)$, Tarassovi $(n=28)$ and Australis $(\mathrm{n}=06)$ as shown in Table 1. Cumulative figure of sera positive for various serovars $(n=146)$ exceed total MAT positive sera $(n=70)$ since several sera reacted with multiple leptospiral serovars. The MAT titres against various serovars ranged between 1:100 and 1:3200.

Higher frequency of seropositives were observed in sows/ gilts $(32.81 \% ; 21 / 64)$ in comparison to boars $(21.30 \%$; $49 / 230)$, mature pigs of $>2$ years $(42.62 \% ; 52 / 122)$ in comparison to young pigs of $<2$ years $(10.47 \% ; 18 / 172)$, cross bred pigs $(29.20 \% ; 33 / 113)$ in comparison to indigenous pigs $(20.44 \%$; 37/181), rural pigs $(24.06 \%$; $51 / 212)$ in comparison to peri-urban pigs $(23.17 \%$; $19 / 82)$, pigs reared in extensive farming system $(32.48 \%$; $38 / 117$ ) in comparison to counterparts in semi-intensive system $(18.08 \% ; 32 / 177)$ and swine which had access to wallowing ponds $(29.56 \% ; 47 / 159)$ than pigs without wallowing access $(17.04 \% ; 23 / 135)$. The higher frequency of seropositives were also observed in pigs which resorted to scavenging $(39.56 \% ; 36 / 91)$ than pigs which were fed concentrates/corn byproducts $(16.75 \% ; 34 / 203)$, swine which had no access to garbage pits $(30.23 \% ; 26 / 86)$ than pigs with garbage access $(21.15 \% ; 44 / 208)$, swine which had contact with other animals $(37.65 \% ; 32 / 85)$ than pigs without animal contact $(18.18 \% ; 38 / 209)$, swine which had no history of reproductive problems $(24.03 \%$; $62 / 258)$ than swine with history of reproductive problems $(22.22 \% ; 8 / 36)$ and swine reared in farms where rodents had access to feeders and waterers $(29.63 \% ; 16 / 54)$ than in farms with limited rodent access $(22.50 \%$; 54/240) (Table 2).

The complete univariate analysis for risk factors for leptospirosis seropositivity in pigs reared in both extensive and semi-intensive system included 11 potential exposure variables. The individual variables that had a $p$ value $<0.25$ in the univariate analysis are highlighted in italics in Table 2. Variables that were significantly associated with 
Table 2: Characteristics of pigs, proportion of MAT results, sero-prevalence and associated odds ratios by their demographic characteristics, (Antibody titre cut-off > 100), Uttar Pradesh, North India, July 2015 to June 2016 (n=294)

\begin{tabular}{|c|c|c|c|c|c|}
\hline \multirow[b]{2}{*}{ Variables } & \multirow[b]{2}{*}{ Variable Categories } & \multirow[b]{2}{*}{ N (\%) } & \multirow[b]{2}{*}{$\begin{array}{l}\text { Positive Cases } \\
\text { by MAT }(\%)\end{array}$} & \multicolumn{2}{|c|}{ Univariate Analysis } \\
\hline & & & & $\begin{array}{l}\text { Unadjusted 'OR' } \\
(95 \% \text { CI) }\end{array}$ & P Value* \\
\hline \multirow[t]{2}{*}{ Age } & Young $(<2$ years $)$ & $172(58.50)$ & $18(10.47)$ & 1 (reference) & $0.001 *$ \\
\hline & Mature $(>2$ years) & $122(41.50)$ & $52(42.62)$ & $6.356(3.467,11.469)$ & \\
\hline \multirow[t]{2}{*}{ Sex } & Female & $64(21.77)$ & $21(32.81)$ & 1 (reference) & $0.056^{*}$ \\
\hline & Male & $230(78.23)$ & $49(21.30)$ & $0.544(0.301,1.020)$ & \\
\hline \multirow[t]{2}{*}{ Breed } & $\begin{array}{l}\text { Cross Bred (Large White } \\
\text { Yorkshire) }\end{array}$ & $113(38.44)$ & $33(29.20)$ & 1 (reference) & $0.086^{*}$ \\
\hline & Non Descript/Local Breed & $181(61.56)$ & $37(20.44)$ & $0.623(0.362,1.072)$ & \\
\hline \multirow[t]{2}{*}{ Location } & Rural & $212(72.11)$ & $51(24.06)$ & 1 (reference) & 0.873 \\
\hline & Peri-Urban & $82(27.89)$ & $19(23.17)$ & $0.952(0.521,1.738)$ & \\
\hline \multirow[t]{2}{*}{ Type of Farming } & Semi-Intensive & $177(60.20)$ & $32(18.08)$ & 1 (reference) & $0.005^{*}$ \\
\hline & Extensive/backyard & $117(39.80)$ & $38(32.48)$ & $2.180(1.265,3.756)$ & \\
\hline \multirow[t]{2}{*}{ Source of Water } & River/Tap Water & $135(45.92)$ & $23(17.04)$ & 1 (reference) & $0.012 *$ \\
\hline & Wallowing pond & $159(54.08)$ & $47(29.56)$ & $2.043(1.163,3.589)$ & \\
\hline \multirow[t]{2}{*}{ Source of Feed } & $\begin{array}{l}\text { Scavenging/ Hotel/kitchen } \\
\text { waste }\end{array}$ & $91(30.95)$ & $36(39.56)$ & 1 (reference) & $0.001 *$ \\
\hline & $\begin{array}{l}\text { Concentrate Feed/Corn } \\
\text { byproducts }\end{array}$ & $20369.05)$ & $34(16.75)$ & $0.307(0.176,0.537)$ & \\
\hline \multirow[t]{2}{*}{ Access to Garbage area } & No & $86(29.25)$ & $26(30.23)$ & 1 (reference) & $0.096^{*}$ \\
\hline & Yes & $208(70.75)$ & $44(21.15)$ & $0.619(0.351,1.092)$ & \\
\hline \multirow{2}{*}{$\begin{array}{l}\text { Contact with other animals } \\
\text { (Water Buffalo, feral pigs) }\end{array}$} & No & 209 (71.09) & $38(18.18)$ & 1 (reference) & $0.001 *$ \\
\hline & Yes & $85(28.91)$ & $32(37.65)$ & $2.717(1.549,4.767)$ & \\
\hline \multirow{2}{*}{$\begin{array}{l}\text { History of Reproductive } \\
\text { problems }\end{array}$} & No & $258(87.76)$ & $62(24.03)$ & 1 (reference) & 0.811 \\
\hline & Yes & $36(12.24)$ & $8(22.22)$ & $0.903(0.391,2.084)$ & \\
\hline \multirow{2}{*}{$\begin{array}{l}\text { Rodent Access to Feeder and } \\
\text { waterers }\end{array}$} & No & $240(81.63)$ & $54(22.50)$ & 1 (reference) & 0.266 \\
\hline & Yes & $54(18.37)$ & $16(29.63)$ & $1.450(0.751,2.800)$ & \\
\hline
\end{tabular}

N, number of animals; total animals-294 swine; OR, 'Odds Ratio'; CI, Confidence Interval of 95\%; * Statistically significant $\leq 0.25$.

seropositivity for porcine leptospirosis after univariate analysis were: mature pigs of $>2$ year old (OR $6.356 ; 95 \%$ CI 3.467 to 11.469 ; $\mathrm{p}$ value $<0.001)$; extensive farming system (OR 2.180; 95\% CI 1.265 to 3.756 ; $p$ value 0.005 ); access to garbage area (OR 3.97; 95\% CI 1.286 to 12.261 ; $\mathrm{p}$ value 0.016 ); access to wallowing pond (OR 2.043; $95 \%$ CI 1.163 to 3.589 ; p value 0.012 ) and contact with other animals such as feral pigs and water buffaloes (OR 2.717; $95 \%$ CI 1.549 to 4.767 ; p value $<0.001)$. Demographic variables such as male sex (OR $0.544 ; 95 \%$ CI 0.301 to $1.020 ; \mathrm{p}$ value 0.056 ) and non-descript breed (OR 0.623; $95 \%$ CI 0.362 to 1.072 ; p value 0.086 ) were found protective against leptospirosis seropositivity. Concentrates/corn byproducts as a source of feed (OR 0.307; 95\% CI $0.176-0.537$; $\mathrm{p}$ value 0.001 ) was also found protective against leptospirosis seropositivity. Interestingly, access of pigs to garbage area (OR 0.619; 95\% CI 0.351-1.092; $\mathrm{p}$ value 0.096) was found as a mitigating factor against leptospirosis seropositivity. After univariate analysis, three variables such as location of study, rodent access to feeder and waterer and history of reproductive problems were excluded from multivariable model since these variables were not statistically associated ( $p$ value $>0.25$ ).

The multivariate analysis for risk factors for leptospirosis seropositivity in pigs included 8 potential exposure 
variables. Risk factors that were significantly associated with seropositivity for porcine leptospirosis after multivariate analysis were: contact with feral pigs and water buffaloes (OR 12.83; 95\% CI 3.72 to 44.26; p value $<0.001$ ), mature pigs of $>2$ year old (OR 12.09; 95\% CI 2.92 to 50.03 ; $\mathrm{p}$ value $<0.001$ ), access to wallowing (OR 8.58 ; $95 \%$ CI 3.34 to 21.93 ; $p$ value $<0.001)$ and access to garbage pits (OR 3.97; 95\% CI 1.29 to 12.26 ; p value 0.016 ) as shown in Table 3. Demographic variable such as non-descript breed (OR 0.22; 95\% CI 0.05 to 0.95 ; p value 0.043 ) was found protective against leptospirosis seropositivity. Three variables such as type of farming system, source of feed and sex were not statistically significant ( $p$ value $>0.05)$.

\section{DISCUSSION}

Global analyses of emerging infectious diseases (EIDs) has identified India as one of the several 'EID hotspots' with leptospirosis included as an important zoonotic disease requiring continuous attention of disease investigators for devising intervention strategies for controlling the disease (Chatterjee et al., 2017). In this study, the clinical signs suggestive of leptospirosis in breeding sows/gilts were restricted to reproductive problems such as higher number of still births and runts per litter, abortion and increase in oestrus interval post weaning. Out of 36 breeding sows showing reproductive problems, only 8 sows showed seropositivity in MAT. Seropositive breeding sows $(n=6)$ with lower MAT titre of $\leq 1: 400$ for both Icterohaemorrhagiae and Grippotyphosa presented clinically at farrowing time with higher number of stillborns per litter and the live piglets born were mostly runts with low birth weight. The presence of stillborns or runts is a typical sign of chronic infection of breeding sows possessing lower MAT titre which cause huge economical losses to piggery units (Ellis, 1999). Two seropositive gilts introduced newly into the breeding stock aborted and had high MAT titre of 1:1600 and 1:3200 for serovar Icterohaemorrhagiae. The high MAT titre in gilts which had aborted suggests that these animals never had prior contact with the infectious agent before being introduced to the herd (Gummowa et al., 1999). Four out of six sows which had still born fetuses and runts showed an increase in oestrus interval post weaning. This finding suggests a detrimental effect of leptospirosis on reproductive organs such as ovaries which control post-weaning oestrus occurrence. The present findings of involvement of serovars Icterohaemorrhagiae and Grippotyphosa with post weaning increase in oestrus interval corroborate with findings of a previous study where an association was drawn between increase in weaning-to-oestrus interval and seroprevalence of serovar Grippotyphosa (Valenca et al., 2013).

The male pigs presented for slaughter showed no clinical signs suggestive of leptospirosis during ante-mortem examination. However, post mortem examination revealed white spots in a few kidney samples in animals seropositive for leptospirosis. It was noticed that the presence of white spots is an unreliable indicator of the presence of agglutinins against leptospirosis since only $66 \%(16 / 24)$ of kidney samples of pigs seropositive for leptospirosis showed white spots in kidneys. Our findings are in concordance with observations of other disease investigators who also reported 'white-spotted kidneys' during post mortem examination in seropositive cases of porcine and ovine leptospirosis respectively (Boqvist et al., 2003; Jarad et al., 2020).

Multivariate analysis by means of non-conditional logistic regression analysis revealed that wallowing in unsanitary ponds and contact of domesticated pigs with wild/feral pigs and water buffaloes were key risk factors for contracting porcine leptospirosis. In the multivariate analysis, it was revealed that the odds for seropositivity in pigs that had contact with these animals were 12.83 times the odds of swine that had no contact with these animals. This observation is in concordance to findings of a previous study in Kenya where higher incidence of leptospirosis was reported in pigs having contact with other animals (Ngugi et al., 2019). Moreover, it was observed that the odds for seropositivity in pigs that had access to wallowing were 8.56 times the odds of swine that had no access to wallowing. Similar report of higher incidence of porcine leptospirosis with access to wallowing area has been reported from Nigeria (Adah et al., 2018).

In this study, we are able to demonstrate that a significant number of pigs $(n=28)$ from U.P. were seropositive for serovar Tarassovi. Pigs are usually considered as the reservoir host for serovar Tarassovi (Lee et al., 2019; Bertasio et al., 2020). However, the authors have demonstrated in a previous study the presence of antibodies against serovar Tarassovi in a few water 
Table 3: Multivariate analysis for risk factors relevant or non relevant with seropositivity by MAT in Swine samples, Uttar Pradesh (July 2015 to June 2016)

\begin{tabular}{|c|c|c|c|c|c|c|}
\hline \multirow{2}{*}{ Variables } & \multirow{2}{*}{$\beta$ coefficients } & \multirow{2}{*}{ S.E. } & \multirow{2}{*}{ odds ratio } & \multicolumn{2}{|c|}{ 95\% C.I. for 'OR' } & \multirow{2}{*}{-P-value } \\
\hline & & & & Lower & Upper & \\
\hline \multicolumn{7}{|l|}{ Age } \\
\hline$<2$ Years & 0 & 0 & 1 (reference) & - & - & \multirow{2}{*}{$0.001^{*}$} \\
\hline$>2$ Years & 2.492 & 0.725 & 12.09 & 2.921 & 50.033 & \\
\hline \multicolumn{7}{|l|}{$\overline{\text { Sex }}$} \\
\hline Female & 0 & 0 & 1 (reference) & - & - & \multirow[b]{2}{*}{0.162} \\
\hline Male & -0.869 & 0.621 & 0.42 & 0.124 & 1.416 & \\
\hline \multicolumn{7}{|l|}{ Breed } \\
\hline $\mathrm{CB}$ & 0 & 0 & 1 (reference) & - & - & \multirow[b]{2}{*}{$0.043^{*}$} \\
\hline Non Descript & -1.51 & 0.745 & 0.22 & 0.051 & 0.952 & \\
\hline \multicolumn{7}{|l|}{ Farming Type } \\
\hline Semi-intensive & 0 & 0 & 1 (reference) & - & - & \multirow{2}{*}{0.911} \\
\hline Extensive & 0.078 & 0.699 & 1.08 & 0.275 & 4.255 & \\
\hline \multicolumn{7}{|l|}{ Access to garbage area } \\
\hline No & 0 & 0 & 1 (reference) & - & - & \multirow{2}{*}{$0.016^{*}$} \\
\hline Yes & 1.379 & 0.575 & 3.97 & 1.286 & 12.261 & \\
\hline \multicolumn{7}{|l|}{$\begin{array}{l}\text { Contact with other animals } \\
\text { (Wild pigs and Water Buffalo) }\end{array}$} \\
\hline No & 0 & 0 & 1 (reference) & & & \multirow{2}{*}{$0.001^{*}$} \\
\hline Yes & 2.552 & 0.632 & 12.83 & 3.72 & 44.259 & \\
\hline \multicolumn{7}{|l|}{ Source of Water } \\
\hline Tap Water/River & 0 & 0 & 1 (reference) & - & - & \multirow{2}{*}{$0.001^{*}$} \\
\hline Wallowing Pond & 2.147 & 0.48 & 8.58 & 3.338 & 21.931 & \\
\hline \multicolumn{7}{|l|}{ Source of Feed } \\
\hline Scavenging/ Hotel/kitchen waste & 0 & 0 & 1 (reference) & - & - & \\
\hline $\begin{array}{l}\text { Concentrate feed/Corn leftover } \\
\text { (Farm waste) }\end{array}$ & 0.288 & 0.541 & 1.33 & 0.462 & 3.849 & 0.594 \\
\hline Constant & -4.129 & 1.209 & - & - & - & - \\
\hline
\end{tabular}

OR, ‘Odds Ratio'; CI, Confidence Interval of $95 \%$; * Statistically significant $\leq 0.05$.

buffalo serum samples $(\mathrm{n}=15)$ in the same geographical location (Deneke et al., 2014). Moreover, there are reports of pigs in India contracting serovar Hardjo (Prameela et al., 2013) whose maintenance host is cattle and water buffalo. Based on this serological evidence, the authors hypothesize that the mixed, backyard type of farming where water buffaloes get chance to wallow in sewage ponds frequented by domestic and feral pigs has led to cross species disease transmission with serovar Tarassovi and serovar Hardjo finding ample opportunity to break the host species barrier to infect water buffalo and pigs respectively. Similar reports of cross species leptospirosis transmission in mixed farming involving cattle and pigs with documented reproductive disorders are available in Belgium (Mori et al., 2017). This trend of wallowing ponds becoming prime hot spots for leptospiral disease transmission is not only restricted to cross species disease transmission but also intra-species disease transmission 
as domesticated pigs can also contract leptospirosis when these animals wallow in sewage ponds frequented by feral pigs. Thus, feral pigs can serve as reservoir hosts for various serovars of Leptospira and poses danger for interspecies transmission of leptospires to humans and other domestic livestock species (Brown et al., 2018).

Multivariate analysis revealed that age of swine was a significant risk factor since mature pigs have 12.09 times the odds of seropositivity than young pigs. The relatively higher number of mature pigs ( $>2$ years) is due to the fact that most of the pigs reared under extensive farming system require longer time period to reach desired slaughter weight due to multi-factorial reasons such as poor nutritive diet, genetic predisposition and high gastro-intestinal parasitic load. These non-descript pigs have ample opportunity for exposure to key risk factors such as access to wallowing in ponds frequented by feral pigs and water buffaloes. Cross bred pigs show good feed conversion ability under semi-intensive care and reaches slaughter weight within a year and has minimum opportunity for exposure to key risk factors during their short life span. Results of significant association of age of swine with seropositivity corroborate with the findings of other disease investigators who suggested the reason to be increased exposure over time (Lee et al., 2019; Ngugi et al., 2019).

Multivariate analysis revealed that access to garbage area might be a significant variable since pigs with access to garbage have 3.97 times the odds of seropositivity than pigs without access to garbage. The garbage pits are frequented by rodents which act as reservoir host for several leptospiral serovars. The sniffing habit of swine exposes their nasal and buccal mucosa as well as mucosa of eyes to rodent urine laden with pathogenic Leptospira. The leptospiral organisms gain entry through minor abrasions in mucous membranes of pigs which frequent rodent infested garbage.

Multivariate analysis seems to suggest that cross bred pigs are apparently at higher risk of contracting leptospirosis than indigenous breeds. This result is in discordance to the findings of Ngugi et al. (2019) who observed no association between porcine breed and Leptospira seropositivity. However, several disease investigators have suggested breed as a risk factor for leptospirosis in bovines and small ruminants. In India, sero-epidemiological studies on bovine leptospirosis have revealed that the risk of leptospirosis was more in exotic breeds followed by indigenous breeds and cross breeds (Balakrishnan et al., 2011). In a sero-epidemiological study in Brazil on ovine leptospirosis, low prevalence of Leptospira spp. was observed by serology and PCR which suggested that the rusticity of the mixed breed sheep may have contributed to the low occurrence of leptospirosis in comparison to pure bred sheep (da Costa et al., 2017). Hence, more studies need to be done to ascertain breed susceptibility in contracting porcine leptospirosis.

Even though multivariate analysis suggests that type of farming is not a significant risk factor (Odds ratio: 1.08; 95\% CI: $0.275-4.255$; P 0.911 ), it is clear that type of farming as a variable may be confounded by the other factors given the difference in results from univariable to multivariable analysis for this variable. The present study revealed that pigs reared in extensive farming system had significantly higher proportion of leptospiral antibodies $(32.48 \%$; 38/117) in contrast to their counterparts reared under semi-intensive system $(18.08 \% ; 32 / 177)$. Pigs grown under backyard farming $(\mathrm{n}=117)$ forage on municipal garbage, have access to sewage for wallowing, reach slaughter weight at older age and are in constant contact with other species of livestock especially water buffaloes due to the mixed farming system adopted in rural areas. Hence, it could be argued that extensive farming system is part of the causal pathway, since this may determine the other significant risk factors discussed above. Moreover, pigs reared under semi-intensive system were not exposed to significant risk factors in the present study such as wallowing, scavenging in garbage pits and contact with other animals which meant that these pigs were less prone to be exposed to leptospirosis.

The Planning Commission of India (1989) has categorized India into 15 agro-climatic zones and U.P. falls in the agroclimatic zone termed Upper Gangetic Plains (Vikaspedia, 2019). Different serovars of Leptospira spp have shown predilection to thrive in specific agro-climatic zones of India (Spatial Variation) (Sabarinath et al., 2018). The present study has revealed spatial variation when comparison was done with previous seroepidemiological studies conducted in other agro climatic zones of India. The serovars Autumnalis $(\mathrm{n}=11)$, Canicola $(\mathrm{n}=10)$ and Hardjo $(\mathrm{n}=15)$ agglutinins present in 133 porcine sera samples in Andhra Pradesh (Prameela et al., 2013) (Agro climatic zone: Southern Plateau and Hills) were all missing in two 
seroepidemiological studies conducted in U.P. from 20112012 and 2016-2017. Further, the presence of agglutinins against serovars Autumnalis $(n=7)$, Canicola $(n=6)$ and Hebdomadis $(\mathrm{n}=4)$ in 177 porcine sera samples in Tamil Nadu (Bojiraj et al., 2017) (Agro climatic zone: East Coast Plains and Hills) and presence of agglutinins against serovar Canicola $(\mathrm{n}=14)$ in 103 porcine sera samples in Kerala (Reshma et al., 2018) (Agro climatic zone: West Coast Plains and Hills), were all missing in U.P. Thus, the present study will further enhance the knowledge regarding the predilection of various leptospiral serovars for different agro-climatic zones of India.

In the present study, we could detect 32 serum samples positive for leptospiral serovar Grippotyphosa. However, a seroepidemiological study conducted in 2011-12 by the same author (Behera et al., 2014) in U.P. failed to detect the presence of serovar Grippotyphosa in all 85 serum samples tested. Moreover, the 2011-12 study detected the presence of agglutinins against serovar Javanica in 12 serum samples which was missing in all the sera samples $(n=294)$ tested in the present study. The above data suggests the relevance of conducting periodic seroprevalence studies on pigs on a regular basis as it helps to unravel temporal variation due to emergence of newer serovars over a period of time which will be missing from existing commercial vaccines and the inclusion of these new serovars help in the preparation of effective vaccines (Klaasen and Adler, 2015). At present, there are no indigenous vaccines available in India and vaccination against porcine leptospirosis is not routinely practiced. This is the reason vaccination was not included as one of the variables while assessing risk factors.

In conclusions, the present study sheds light on the role played by faulty swine husbandry practices such as providing swine accessibility to unsanitary wallowing ponds and practicing mixed farming in which water buffaloes are kept in pig farm premises as the precipitating factors in the spread of porcine leptospirosis. Further, feral pigs and water buffaloes pose serious threat for crossspecies transmission of leptospires to domesticated pigs.

\section{ACKNOWLEDGEMENTS}

The authors wish to thank Indian Council of Agricultural Research (ICAR) for providing financial support since part of this work was funded by ICAR Network project on Outreach Programme on Zoonotic Diseases (OPZD)
(ICAR Grant number 3021). The authors also wish to thank the Director, IVRI for providing logistical support for this research work.

\section{REFERENCES}

Adah, B.M.J., Kwanashie, C.N., Kazeem, H.M. and Mailafia, S. 2018. Prevalence of Leptospira Spp. Serovar Bratislava in Pigs from kaduna State, Nigeria using Competitive -ELISA. IOSR-JAVS, 11(2): 11-16.

Atherstone, C., Mgode, G.F., Dhand, N.K., Alonso, S., Grace, D., Ward, M.P. and Mor, S.M. 2020. Selected endemic zoonoses in pigs presenting for slaughter in Kampala, Uganda. Am. $J$. Trop. M. Hyg., 103(6): 2552-2560.

Balakrishnan, G., Roy, G.P., Govindarajan, R., Ramaswamy, V. and MuraliManohar, B. 2011. Seroepidemiological studies on leptospirosis among bovines in organized farm. IJAVMS, 5(6): 511-519.

Behera, S.K., Sabarinath, T., Chaudhary, P., Kumar, A., Das, S.C. and Agarwal, R.K. 2014. Evaluation of recombinant lip132 based latex agglutination test for serodiagnosis of porcine leptospirosis. Vet. World, 7(1): 17-20.

Bertasio, C., Papetti, A., Scaltriti, E., Tagliabue, S., D’ Incau, M. and Boniotti, M.B. 2020. Serological survey and molecular typing reveal new Leptospira serogroup Pomona strains among pigs of northern Italy. Pathogens, 9: 332-354.

Bhatia, M. and Umapathy, B.L. 2015. Deciphering leptospirosis-a diagnostic mystery, an insight. IJMRHS, 4: 693-701.

Bojiraj, M., Porteen, K., Gunaseelan, L. and Kannan, S. 2017. Seroprevalence of Leptospirosis in Animals and Its Public Health Significance. Int. J. Livest. Res., 7(11): 220-226.

Boqvist, S., Montgomery, J.M., Hurst, M., Thu, H.T., Engvall, E.O., Gunnarsson, A. and Magnusson, U. 2003. Leptospira in slaughtered fattening pigs in southern Vietnam: presence of the bacteria in the kidneys and association with morphological findings. Vet. Microbiol., 93: 361-368.

Brown, V.R., Bowen, R.A. and Bosco-Lauth, A.M. 2018. Zoonotic pathogens from feral swine that pose a significant threat to public health. Transbound. Emerg. Dis., 65(3): 649659 .

Chatterjee, P., Bhaumik, S., Chauhan, A.S. and Kakkar, M. 2017. Protocol for developing a Database of Zoonotic disease Research in India (dozoori). BMJ Open, 7: e017825.

Cook, E.A.J., de Glanville, W.A., Thomas, L.F., Kariuki, S., Bronsvoort, B.M.C. and Fèvre, E.M. 2017. Risk factors for leptospirosis seropositivity in slaughterhouse workers in western Kenya. Occup. Environ. Med., 74(5): 357-365.

da Costa, D.F., da Silva, A.F., de Lima Brasil, A.W., Loureiro, A.P.P., dos Santos, F.A., de Azevedo, S.S., Lilenbaum, W. 
and Alves, C.J. 2017. Leptospirosis in native mixed-breed sheep slaughtered in a semiarid region of Brazil. Cienc. Rural, 47(2): e20160563.

dos Santos, C.V.B., Mathias, L.A., Feitosa, P.J.S., Oliveira, J.M.B., Junior, J.W.P. and Brandespim DF. 2019. Risk factors associated with leptospirosis in swine in state of Pernambuco, Brazil. Arq. Inst. Biol., 86: 1-8.

Deneke, Y., Sabarinath, T., Gogia, N., Lalsiamthara, J., Viswas, K.N. and Chaudhuri, P. 2014. Evaluation of recombinant ligb antigen-based indirect ELISA and latex agglutination test for the serodiagnosis of bovine leptospirosis in India. Mol. Cell. Probes., 28(4): 141-146.

Divers, T.J. 2018. Leptospirosis in swine. MSD Manual Veterinary Manual. https://www.msdvetmanual.com/ generalized-conditions/leptospirosis/leptospirosis-in-swine

Ellis, W.A. 1999. Leptospirosis. In: Diseases of Swine, Eighth edition, Iowa state University Press, Ames, Iowa, USA, pp. 483-493.

Gummowa, B., Myburghb, J.G., Thompsonc, P.N., van der Lugtd, J.J. and Spencer, B.T. 1999. Three case studies involving Leptospira interrogans serovar Pomona infection in mixed farming units. J. S. Afr. Vet. Assoc., 70(1): 29-34.

Herrmann-Storck, C., Saint Louis, M., Foucand, T., Lamaury, I., Deloumeaux, J. and Baranton, G. 2010. Severe leptospirosis in hospitalized patients, Guadeloupe. Emerg. Infect. Dis., 16(2): 331-334.

Jarad, A.S., AL-Kubaisi, S.M.A., Abdulkhaliq, R.J. and Hasan, M.S. 2020. Bacteriological and pathological study on kidneys of slaughtered sheep in Fallujah city. Indian J. Med. Forensic Med. Toxicol., 14(1): 665-671.

Klaasen, H.E. and Adler, B. 2015. Recent advances in canine leptospirosis: focus on vaccine development. Vet. Med. (Auckl), 6: 245-260.

Lee, H.S., Thanh, T.L., Ly, N.K., Nguyen-Viet, H., Thakur, K.K. and Grace, D. 2019. Seroprevalence of leptospirosis and Japanese encephalitis in swine in ten provinces of Vietnam. PLoS One, 14(8): e214701.

Mori, M., Bakinahe, R., Vannoorenberghe, P., Maris, J., de Jong, E., Tignon, M., Marin, M., Desqueper, D., Fretin, D. and Behaeghel, I. 2017. Reproductive disorders and leptospirosis: a case study in a mixed-species farm (cattle and swine). Vet. Sci., 4(4): 64.

Ngugi, J.N., Fèvre, E.M., Mgode, G.F., Obonyo, M., Mhamphi, G.G., Otieno, C.A. and Cook, EAJ. 2019. Seroprevalence and associated risk factors of leptospirosis in slaughter pigs; a neglected public health risk, western Kenya. BMC Vet. Res., 15: 403 .
Pozzi, P., Alborali, G.L., Etinger, M. and Hadani, Y. 2020. Epidemiological investigation of the prevalence of Leptospira spp. in pigs in Israel. Isr. J. Vet. Med., 75: 14-21.

Rani Prameela, D., Sreenivasulu, D., Vijayachari, P. and NatarajSeenivasan, N. 2013. Seroepidemiology of leptospirosis in Andhra Pradesh. Arch. Clin. Microbiol., 4(6): 2.

Reshma, P.S., Mini, M., Ambily, R., Joseph, S., Usha, A.P., Reji, R.M., Aiswarya, N. and Akkara, T.S. 2018. Seroprevalence of leptospirosis among swine in Kerala, India. Pharm. Innov., 7(9): 101-103.

Sabarinath, T., Behera, S.K., Deneke, Y., Atif Ali, S., Kaur, G., Ashok Kumar, T., Ravi Kumar, G., Senthil Kumar, K., Sinha, D.K., Verma, M.R., Srivastava, S.K. and Chaudhuri, P. 2018. Serological evidence of anti-Leptospira antibodies in goats in various agro climatic zones of India. Small Rumin. Res., 169: $74-80$.

Sperandei, S. 2014. Understanding logistic regression analysis. Biochem. Med. (Zagreb), 24 (1): 12-18.

Strutzberg-Minder, K., Tschentscher, A. and Beyerbach, M. 2018. Passive surveillance of Leptospira infection in swine in Germany. Porc. Health Manag., 4: 10.

USDA (United States Department of Agriculture): National Veterinary Services Laboratories. 1987. Microtitre technique for detection of Leptospira antibodies. Proc. Annu. Meet. U. S. Anim. Health Assoc., 91: 65-73.

Valenca, R.M.B., Mota, R.A., Castro, V., Anderlini, G.A., Pinheiro Junior, J.W., Brandespim, D.F., Valenca, S.R.F.A. and Guerra, M.M.P. 2013. Prevalence and risk factors associated with leptospira spp. infection in technified swine farms in the state of Alagoas, Brazil risk factors associated with leptospira spp. in swine farms. Transbound. Emerg. Dis., 60: 79-86.

Verma, V., Goyal, M., Kala, D., Gupta, S., Kumar, D. and Kaushal, A. 2020. Recent advances in the diagnosis of leptospirosis. Front. Biosci., 25: 1655-1681.

Vikaspedia. 2021. Agro climatic zones in India. https:// vikaspedia.in/agriculture/crop-production/weatherinformation/agro-climatic-zones-in-india.

Vincent, A.T., Schiettekatte, O., Goarant, C., Neela, V.K., Bernet, E., Thibeaux, R., Ismail, N., Khalid, M.K.N.M., Amran, F., Masuzawa, T. et al. 2019. Revisiting the taxonomy and evolution of pathogenicity of the genus Leptospira through the prism of genomics. PLOS Negl. Trop. Dis., 13(5): e0007270.

Wasiński, B. 2014. Infections of swine caused by leptospira serovars of serogroup Sejroe possibilities of recognition with the use of PCR. Bull. Vet. Inst. Pulawy, 58: 521-526. 